\title{
The neuroendocrine signal for ovulation
}

\author{
Fred J. Karscha, Suzanne M. Moenter and Alain Caraty ${ }^{\mathbf{b}}$ \\ "Reproductive Sciences Program and Department of Physiology, University of Michigan, Ann Arbor. \\ MI, 48109-0404, USA \\ 'Station de Physiologie de la Reproduction, Institut National de la Recherches Agronomique. \\ Nowzilly, France
}

\begin{abstract}
Karsch, F J., Moenter, S.M, and Caraty, A., 1992. The neurcendocrine signal for ovulation. Anim. Reprod. Sci., 28: 329-341.

The central nervous system plays a crucial role in determining if and when ovulation occurs. This neural regalation of ferility is achieved, in large measure, by means of the secretion of gunadotropin releasing hormone (GnRH) from the hypothalamus. This report addresses changes in the secretion of GnRH into hypophyseal portal blood, and the regulation of these changes, leading up to ovulation in the domestic sheep. During the estrous cycle, the process of ovulation is heralded by a large preovulatory surge in the secretion of luteinizing hormone (LH). Recent studies have provided sirong evidence that this LH discharge is induced by an unambiguous surge in the secretion of GrRH into hypophyseal portal blood. This surge of GnRH is massive and sustained, and is triggered by the iticrease in circulating estradiol secreted from the developing preovulatory ovarian follicles. Although the mechanism by which the increment in estradiol activates the $\mathrm{GnRH}$ neuronal network remains io be determined, this process involves a switch in the pattern of GnRH secretion. At the time of this switch, a pattern of $\mathrm{GnRH}$ release that is strictly episodic at other times of the estrous cycle gives way to a surge that sustains a continuous elevation of GnRH in portal blood for many hours. This swirch in the operation of the GnRH neurosecretory system, and the resultant massive release of GnRH. constitutes the neuroendocrine signal for ovulation.
\end{abstract}

\section{INTRODUCTION}

A prerequisite for fertility in females is ovulation. The existence of a neural signal for this process was first proposed during the middle of this century when electrical stimulation of the brain was found to induce ovulation in rabbits (Marshall and Verney, 1936). The discovery that hypothalamic extracts stimulated secretion of anterior pituitary hormones controlling reproduction (McCann et al., 1960) suggested that this signal is neuroendocrine in nature. In the late $1960 \mathrm{~s}$, the advent of radioimmunoassays allowed definition of the pituitary signal for ovulation as a sharp preovulatory surge in the secretion of luteinizing hormone ( $\mathrm{LH}$ ) (Midgley and Jaffe, 1966; Niswender et al., 1968; Monroe et al., 1969). The idea that this pituitary signal is initiated by a neuroendocrine signal was strengthened in the 1970 s by the structural identifi-

Correspondence to: F.J. Karsch, Reproductive Sciences Program and Department of Physiology, University of Michigan, Ann Arbor, MI, 48109-0404, USA. 
cation and synthesis of gonadotropin-releasing hormone (GnRH) (Amoss et al., 1971 ; Schally et al., 1971), and the demonstration that injection of GnRH induced a preovulatory-like surge of LH (Cumming et al., 1972; Martin et al., 1974).

Despite the generai acceptance of a role for the brain in ovulation, definitive demonstration and characterization of a neuroendocrine signal for ovulation has proven difficulc. There is convincing evidence the hypothalamus secretes brief bursts, or pulses, of $\mathrm{GnRH}$ into the hypophyseal portal vessels and that this episodic release is necessary for the maintenance of gonadal function through the stimulation of yulsatile $\mathrm{LH}$ secretion (Clarke and Cummins, 1982; Levine and Ramirez, 1982; Levine et al., 1985). Whether or not there is an additional neuroendocrine signal for ovulation over and above the episodic GnRH discharges became a matter of considerable debate that, for some species, continues to this day. Studies in anesthetized laboratory rats provided the first evidence for increased GnRH release into hypophyseal portal blood at the tine of the preovulatory LH surge (Sarkar et al, 1976). In other speries, however, heightened GnRH secretion at this time of the cycle was neither, n ormly identified nor accepted as being important for ovulation (Knobil et al., 1980; Clarke et al., 1987). The primary impediment to defining and studying a neuroendocrine signal for ovulation has been difficulty in monitoring the pattern of hypothalamic substances, such as GnRH, released into hypophyseal portal blood.

In the early 1980 s, a method for obtaining sequential samples of blood from the hypophyseal portal system of undisturbed sheep was developed by Clarke and Cummins (1982). Subsequent modifications of this procedure by Caraty and Locatelli (1988) allowed sampling of portal blood from the same animal for up to 48 consecutive hours, a period sufficient to encompass the entire LH surge. Over the past few years, we have used this approach to study the pattern of GnRH secretion leading up to ovulation in the ewe, and have identified a large and sustained preovulatory surge of this hypothalamic hormone. This report summarizes these findings and those of subsequent experiments to examine mechanisms generating this neuroendocrine signal for ovulation.

\section{THE PREOVULATORY GRRH SURGE}

The follicular phase of the ovine estrous cycle, defined as the interval between luteolysis and ovulation, spans a period of 3-4 days during which there is dynamic interplay among hormones of the hypothalamo-hypophysealgonadal axis. When we began our studies of GnRH secretion, feedback interactions had been well established in terms of LH, estradiol and progesterone (Goodman, 1988). Progesterone was known to suppress pulsatile LH release; frequency of LH pulses is thus low before regression of the corpus luteum. As progesterone declines with luteal demise, this inhibition is removed and LH- 
pulse frequency increases. The resulting rise in circulating $\mathrm{LH}$ provides a stimulus for the follicular phase increase in estradiol secretion from ovarian follicles. Estradiol, in turn, elicits the surge of LH that causes ovulation and initiates luteinization.

Considerable insight into how GnRH fits into this scheme was initially provided by Clarke and colleagues (1987). During the luteal phase, they found GnRH to be released as discrete pulses, the frequency of which is relatively low. To a large extent, this low frequency is due to the elevation in circulating progesterone, which inhibits pulsatile GnRH secretion when present at luteal phase concentrations (Karsch et al., 1987). This inhibition dissipates with the drop in circulating progesterone at luteolysis, allowing an increase in GnRH-pulse frequency spanning the interval from luteolysis to onset of the preovulatory LH surge. The secretory dynamics of GnRH at the time of the preovulatory LH surge, however, remained open to question in this initial descriptive study due to an inconsistency of results.

In our laboratories, we monitored the time course of $\mathrm{GnRH}$ secretion leading up to ovulation in the ewe using the technique of Caraty and Locatelli (1988) for sampling hypophyseal portal blood (Moenter et al., 1991; Barrell et al., 1992). We found that, much as reported by Clarke et al. (1987), GnRHpulse frequency increased from about 1 pulse per $4 \mathrm{~h}$ to about 1 pulse per 45 min as the cycle progressed from luteal to ea-ly follicular phase. An example of this change is presented in Fig. 1 . It should be stressed that during the luteal and early to mid-follicular phases of the cycle, GnRH release is strictly episodic. As the follicular phase progressed to the preovulatory LH surge, the pattern of GnRH secretion changed dramatically. Specifically, pulses of GnRH gave way to a massive and sustained surge.

A particularly illustrative example of the dynamics of $\mathrm{GnRH}$ release leading to ovulation is provided in Fig. 2, which describes the time course of GnRH in portal blood sampled continuously from a ewe for $48 \mathrm{~h}$ spanning most of the foilicular phase. Several points are of particular interest. First, the preovulatory rise in circulating estradiol in the early to mid-follicular phase was associated with a reduction in GnRH-pulse amplitude and an increase in pulse frequency (the latter change is obscured by the scale in Fig. 2). This suggests that the rising tide of estradiol enforces feedback regulation of pulsatile GnRH secretion prior to onset of the LH surge, a possibility we are currently testing. Second, there was a robust surge of $\mathrm{GnRH}$. This surge began with onset of the LH discharge and reached values 90 -fold greater than the pre-surge baseline in the example shown in Fig. 2. A surge pattern of GnRH was evident in each of 11 ewes in which portal blood was sampled during at 'tasi a portion of the preovulatory LH discharge. Third, although onsets of the GnRH and LH surges were coincident, the GnRH surge persisted well after the LH surge had ended and, in some instarces, GnRH was just reaching its peak as LH was approaching baseline. This indicates that the LH surge ends for reasons other 

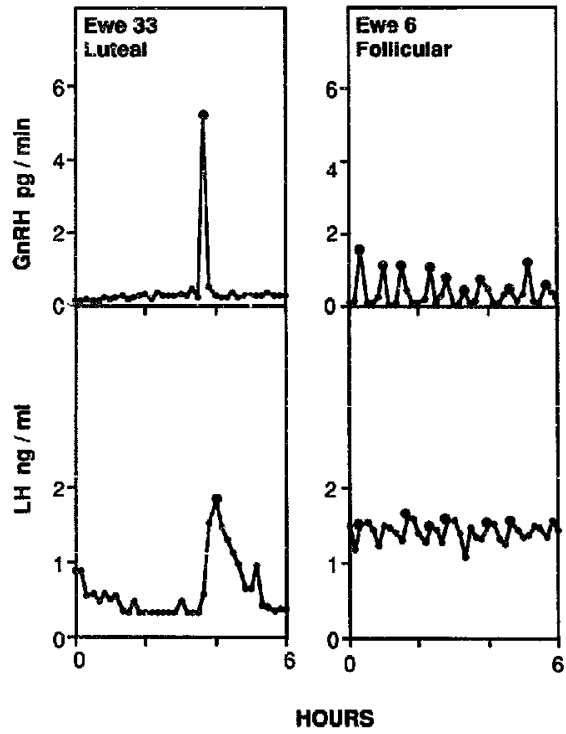

Fig. 1. Representative patterns of GnRH in portal blood and LH in peripheral blood of a ewe in the luteal (left) and early follicular phases (right) of the estrous cycle. Large points depict peaks of identified GnRH and LH pulses. Adapted from Barrell et al. (1992).

than a lack of $\mathrm{GnRH}$. Fourth, adjacent $\mathrm{GnRH}$ values during the surge were highly variable, but GnRH did not return to baseline until its surge had ended. This is relevant with respect to the moment-to-moment secretcry pattern of GnRH during the surge, an issue considered in greater depth later in this report.

Our findings provide definitive evidence for the existence of a robust preovulatory GnRH surge in the ewe. Similar results were recently obtained by Dománski et al. (1991) who utilized push-pull perfusion of the median eminence to obtain samples for assessing $\mathrm{GnRH}$ release. It is important to point out that a large and abrupt increase in GnRH was found, in other studies, to be indispensable for induction of the LH surge in this species (Kaynard et al., 1988; Clarke et al., 1989). It may be concluded, therefore, that the neuroendocrine signal for ovulation in the ewe consists of a sustained surge of GnRH 


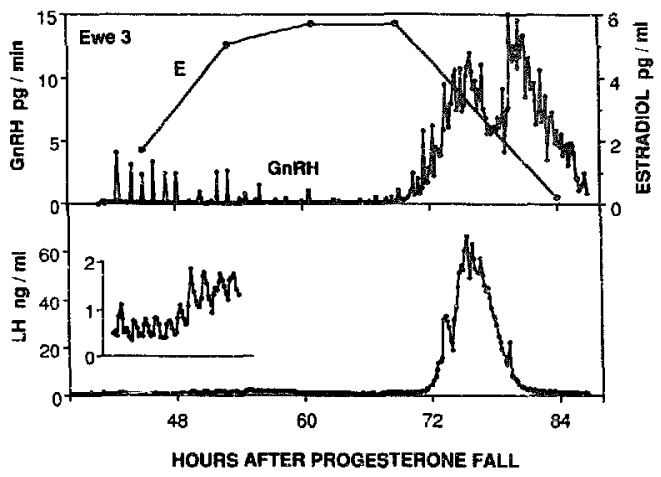

Fig. 2. Patterns of GnRH in portal blood and estradiol (E) and LH in peripheral blood of a ewe in the follicular phase of the estrous cycle. Inset in lower panel amplifies vertical axis and reveals LH pulse pattern otherwise obscured by scale. Horizontal axis refers to time after removal of progesterone implants to initiate follicular phase. Adapted from Moenter et al. (1991).

that travels to the pituitary gland via the hypophyseal portal system. The next issue to be addressed pertains to the role of estradiol in induction of this surge.

\section{ESTRADIOL-INDUCFD CnRH SURGE}

The first studies of the effects of estradiol on GnRH secretion in the ewe described the response to injections of large doses of estradiol in long-term ovariectomized ewes (Clarke and Cummins, 1985; Schillo et al., 1985). The patterns of GnRH observed in those studies, however, were not consistent among animals, with large increases in Gn $\overline{\mathrm{K}} \overline{\mathrm{H}}$ release observed at the time of the LH surge in some sheep but not in others. Subsequent studies provided more consistent evidence that large doses of estradiol stimulate GnRH secretion coincident with the induced LH surge in the ewe (Clarke, 1988; Caraty et al., 1989). More recently, we have investigated the mechanism of GnRH.surge induction using an experimental model in which the steroidal milieu of the follicular phase of the estrous cycle is simulated experimentally to produce an 'artificial follicular phase' (Moenter et al., 1990).

To set up the artificial follicular phase model, ewes are ovariectomized and immediately treated with subcutaneous Silastic implants to produce mid-luteal phase concentrations of progesterone and estradiol in serum. After progesterone has been maintained for a period approximating the duration of the luteal phase, progesterone implants are removed to simulate luteolysis and 
estradiol is increased, by placement of additional implants, to produce a peak follicular phase concentration of estradiol. Earlier studies had characterized this model in terms of LH secretion and had determined that preovulatorylike surges of LH occur with regularity and are precisely timed (Goodman et al., 1981 ). The model has the advantage of allowing neuroendocrine signals for ovulation to be investigated within the time frame of the follicular phase using a physiologic concentration of estradiol in an arimal that has never been deprived of the feedback influences of gonadal steroids.

A typical pattern of $\mathrm{GnRH}$ secretion during the $\mathrm{LH}$ surge induced in the artificial follicular phase model is illustrated in Fig. 3. Before onset of the LH surge, GnRH secretion was suppressed; pulses of GnRH occurred but were extremely low in amplitude presumably due to a negative feedback effect of the peak follicular phase concentration of circulating estradiol. The low rate of $\mathrm{GnRH}$ secretion was then interrupted by an unambiguous surge of $\mathrm{GnRH}$, a response observed in each of 32 animals studied to date. The induced GnRH surge is essentially indistinguishable from the spontaneous preovulatory GnRH surge. It is extremely high in amplitude, typically exceeding the presurge baseline by more than 100 -fold. It begins together with, but continues well beyond the induced LH surge. It consists of a continuous elevation above the pre-surge baseline and exhibits considerable variation among adjacent values. Additional studies have documented that the GnRH surge does not

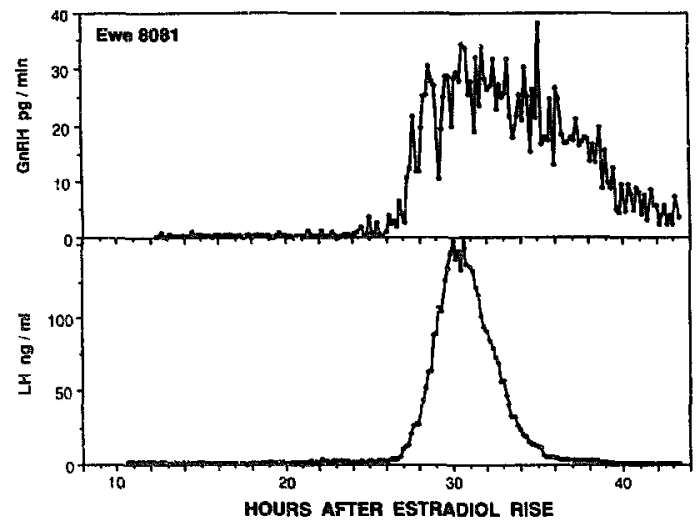

Fig. 3. Representative pattern of $\mathrm{G} R \mathrm{RH}$ in portal blood and $\mathrm{LH}$ in peripheral blooc during surge induced in artificial follicular phase model. Horizontal axis refers to cime after placement of estradiol implants. Redrawn from Moenter et al. (1990). 
occur if no estradiol is administered following progesterone withdrawal (Moenter et al., 1990).

The experimental induction of a preovulatory-like surge of $\mathrm{GnRH}$ in the artificial follicular phase model provides compelling evidence that the follicular phase rise in circulating estradiol causes an abrupt and robust activation of the GnRH neurosecretory system prior to ovulation in the ewe. Moreover, it establishes a powerful experimental system for studying other aspects of the physiologic regulation of the GnRH surge. In one such study, we have observed that the induced GnRH surge is blocked by an elevation in circulating progesterone, thereby accounting for the absence of gonadotropin surges during the luteal phase despite occasional rises in circulating estradiol (KasaVubu et al., unpublished data, 1992). In another study, the GnRH surge was found to be induced equally well in the breeding and anestrous seasons, indicating that the seasonal absence of ovulation is not the consequence of a specific alteration of the GnRH-surge generating mechanism but is due to lack of activation of this mechanism (Moenter et al., 1990). Moreover, we have used the artificial follicular phase model to investigate the moment-to-moment secretory dynamics of GnRH during the surge (Moenter et al., 1992b). This aspect of our studies is described in the next section of this report.

\section{MODE OF ACTIVATION OF THE GRRH NEUROSECRETORY SYSTEM}

The massiv and sustained nature of the GriRH surge during either the natural or artificial follicular phase raises intriguing questions related to the mode of activation of the GnRH neuronal network. Does estradiol induce the GnRH surge by accelerating or heightening the episodic pattern of release? Aiternatively, does estradiol elicit the surge by causing a switch in the pattern of secretion from one that is strictly episodic to one that produces a continuous elevation of GnRH in portal blood? On the one hand, pulsatile secretion is suggested by the large variability among adjacent values during the surge (Figs. 2 and 3 ). Indeed, earlier studies led to the conclusion that GnRH-pulse frequency increases during the estradiol-induced surge in the ewe (Clarke and Cummins, 1985; Caraty et al., 1989). On the other hand, our observation of a continuous elevation of GnRH far in excess of baseline throughout the surge raises the possibility that GnRH release may not be strictly episodic at this time.

The persistent elevation of GnRH during the surge becomes pertinent when viewed in the context of several assumptions related to the fate of GnRH once it enters the portal circulation. Specifically, we assume our technique detects GnRH on its only pass through the portal system. There is no detectable recirculation of GnRH from the periphery due to its rapid metabolism and dilution in the rast volume of peripheral blood. (We find that GnRH is undetectable in peripheral blood even during the massive surge of its secretion.) 
It follows, therefore, that GnRH molecules detected in a given sample of portal blood must have entered the portal system while the sample was being collected. Further, if GnRH secretion is strictly episodic, it follows that values must fall precipitously to an undetectable baseline between pulses. This is rather different from the fate of the LH molecule which, after its release from the pituitary, recirculates in detectable concentrations that progressively decline with catabolism.

If the foregoing assumptions are valid, then two explanations may be forwarded for the persistent elevation of $\mathrm{GnRH}$ in portal blood during the surge. Either GnRH secretion is not strictly episodic, or the surge is composed of extremely frequent pulses but the sampling schedule of our experiments was not sufficient to reveal the true pattern of release. With regard to the latter explanation, it is important to stress that portal blood in our studies described to this point had been sampled continuously and separated into 10 -min fractions during the surge. Thus, GnRH-containin/5 blood (during a pulse) could have been combined with non-GnRH-containing blood (between pulses), masking a secretory pattern that is strictly episodic. In an attempt to resolve this issue, we employed a highly frequent sampling schedule to characterize moment-to-moment GnRH release during the surge induced in our artificiai follicular phase model.

The first step in this study was to validate the assumptions (stated above) concerning the fate of GnRH once it enters the portal system, and to assess the suitability of our sampling technique for characterizing moment-to-moment patterns of release. For this purpose we monitored the dynamics of GnRH patterns in portal blood using hinging frequent sampling under conditions in which release is known to be wactly episodic, specifically in the ovariectomized ewe (Moenter et al. 1\% 2a). Hurophyseal portal blood was obtained at 30-s intervals freis arieg ined ewes to characterize GnRH patterns in terms of abrugness of irtesse and decrease during a pulse, duration of a pulse and inter-pulse brisciine.

A representative pattern is illustrated in Fig. 4. The contour of most GnRH pulses approximated a square wave with a steep ascent (rising as much as 50 fol within $1 \mathrm{~min}$ ), a release period averaging $5.5 \mathrm{~min}$ and a precipitous descent to near the pre-pulte baseline within 2-3 min. The inter-pulse baseline remained essentially undetectable until the explosive onset of the next GnRH pulse. Distortion of the GnRH pattern by the sampling procedure was found to be minimal, as assessed in vitro by application of square-wave GnRH patterns to our sampling apparatus by means of a syringe pump and collection through the blood withdrawal system (Moenter et al., 1992a). Moreover, based on mathematical convolution anaiysis performed on data obtained from this in vitro system, we calculated that discrete pulses could be resolved if the interval between release periods was as brief as $1 \mathrm{~min}$ (R.M. Brand, A.R. Midgley, Jr., S.M. Moenier and F.J. Karsch, unpublished data, 1991). 


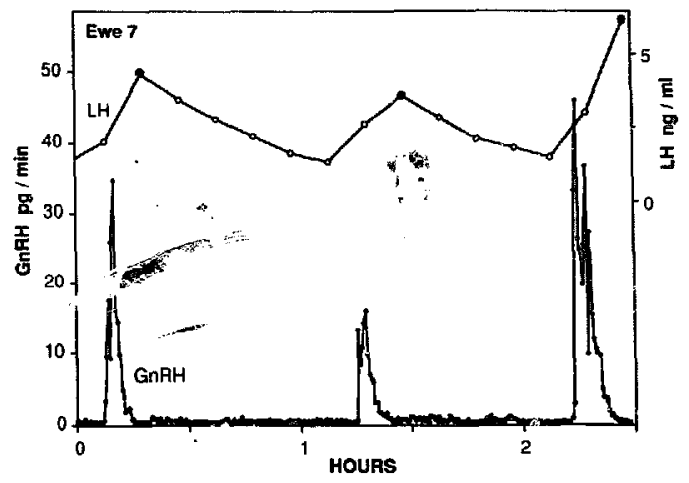

Fis. 4. Representative patterns of GnRH in portal blood and LH in peripheral blood (solid points depict peaks of identified $L H$ pulses) in an ovariectomized ewe. Portal samples for GnRH measurement obtained every $30 \mathrm{~s}$; jugular samples for LH measurement taken every $10 \mathrm{~min}$. Redrawn from Moenter et al. (1992a).

Three con iusions seem warranted from this validation study. First, accuracy of our portal-blood collection technique is sufficient to characterize the moment-to-moment pattern of GnRH release. Second, under conditions in which GnRH secretion is strictly episodic, GnRH salues return rapidly to an undetectable baseline between pulses. Third, if GnRH is secreted in a strictly episodic manner during the surge, individual pulses would be obscured with 3G-s sampling only if the interval between secretory bursts is very short, of the order of 1 min or less.

Our next step $\because$ as to employ the rapid sampling procedure to characterize the dynamics of GnRH secretion during the surge induced in the artificial follicular phase model (Moenter et al., 1992b). Because the GnRH surge is so prolonged (about $18 \mathrm{~h}$ ) and its onset can vary by several hours among sheep, we chose to monitor GnRH secretion during several 'windows' of 30-s samples obtained at the expected time of the GnRH surge (two to five windows in each of 12 ewes). Results from a representative individual are presented in Fig. 5. Although the differences among contiguous values were greater than the variation in our GnRH assay, suggesting a fluctuating rate of release, $\mathrm{GnRH}$ remained continuously elevated above the basal vaiue (less than $0.5 \mathrm{pg} \mathrm{min}-1$ ) throughout each window of 30-s samples obtained during the surge in the example illustrated in Fig. 5. Thus, there was no convincing evidence for a strictly episodic secretion of $\mathrm{GnRH}$.

Of the 12 ewes sampled in this fashion, data consistent with a strictly epi- 

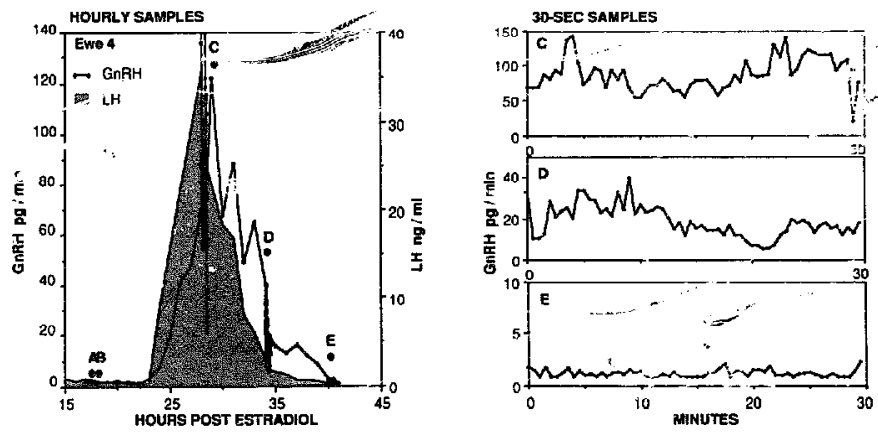

Fig. S, Left: Pattern of GnRH in portal blood (solid points) and LH in peripheral blood (shaded area ) in samples obtained hourly. A-E designate times that five 'windows' of ponal blood were obtained at 30-s intervals for 30 min. Right: Pattern of GnRH in three sampling 'windows' (C,D,E) that occurred during the GnRH surge. From Moenter et al. (1992b).

sodic secretion during the surge were obtained in only one window of one ewe. It is of interest that the GnRH pattern in another ewe sampled at the very onset of the surge is consistent with very large and highly frequent pulses (about 1 pulse per $15 \mathrm{~min}$ ). The apparent pulses of $\mathrm{GnRH}$ in this instance, however, werc superimposed upon a rising component of continuously elevated values and they gave way, after some $60 \mathrm{~min}$, to a pattern indistinguishable from those illustrated in Fig. 5.

The overwhelming majority of our data in these studies supports the conclusion that the pattern of GnRH secreted into hypophyseal portal blood is not exclusively episodic during the surge. This, in turn, raises the possibility that estradiol induces the surge by causing a switch in the firing pattern of $\mathrm{GnRH}$ neurons from one which is strictly episodic to one that leads to a continuous discharge of GnRH into the portal circulation. Such a switch, occurring $16-24 \mathrm{~h}$ after the rise in circulating estradiol, could reflect one of several mechanisms including a desynchronization of $\mathrm{GnRH}$ neurons that previously fired in unison, the recruitment of a surge-specific population of GnRH neurons that fire in a non-synchronous fashion, or an extreme acceleration of the frequency of episodic release such that the interval between bursts is shorter than can be resulved by our experimental system (less than $1 \mathrm{~min}$ ). Although our findings do not rule out a component of episodic secretion during the surge, they provide evidence that, to induce the surge, estradiol does more than merely augment pulsatile $\mathrm{GnRH}$ release. 


\section{CONCLUSIONS}

The studies summarized in this report demonstrate that the neuroendocrine signal for ovulation in the ewe consists of a surge of $\mathrm{GnRH}$ released from nerve terminals in the median eminence into hypophyseal portal blood. This surge is massive and sustained, and it is triggered by the preovulatory increase in estradiol secreted by the developing ovarian follicles. Although the mechanism by which the increment in estradiol activates the GnRH neuronal network remains to be elucidated, this process involves a switch in the mode of operation of the GnRH neurosecretory system. At the time of this switch, a mode of GnRH release that had been strictly episodic gives way to a surge that sustains an elevation of $\mathrm{GnRH}$ in portal blood for many hours.

\section{ACKNOWLEDGMENTS}

Studies in the USA were supported by NIH-HD-18337 and USDA 90 37240-5507 grants. Studies in France were supported by the Institut National de la Recherches Agronomique.

\section{REFERENCES}

Amoss, M.,Burgus, R., Blackwell, R., Vale, W., Fellows, R. and Guillemin, R., 1971. Purification, amino acid composition and $\mathrm{N}$-terminus of the hypothalamic luteinizing hormone releasing factor (LRF) of ovine origin. Biochem. Biophys. Res. Commun., 44: 205-210.

Barrell, G.K., Moenter, S.M., Caraty, A. and Karsch, F.J., 1992. Seasonal changes in gonadotropin releasing hormone secretion in the ewe. Biol. Reprod., 46: 1130-1 135.

Caraty, A. and Locatelli, A., 1988. Effect of time after castration on secretion of LHRH and LH in the ram. J. Reprod. Fertil., 82: 263-269.

Caraty, A., Locatelli, A. and Martin, G.B., 1989. Biphasic response in the secretion of gonadotrophin-releasing hormone in ovariectomized ewes injected with oestradiol. J. Endocrinol, 123: 375-382.

Clarke, I.J., 1988. Gonadotrophin-releasing hormone secretion (GnRH) in anoestrous ewes and the induction of GnRH surges by oestrogen. J. Endocrinol., 117: 355-360.

Clarke, I.J. and Cummins, J.T., 1982. The temporal relationship between gonadotropin releasing hormone $(\mathrm{GnRH})$ and luteinizing hormone ( $\mathrm{LH})$ secretion in ovariectomized ewes. Endocrinology, 111:1737-1739.

Clarke, I.J. and Cummings, J.T., 1985. Increased gonadotropin-releasing hormone pulse frequency associated with estrogen-induced luteinizing hormone surges in ovariectomized ewes. Endocrinology, 116: 2376-2383.

Clarke, I.J., Thomas, G.B., Yao, B. and Cummins, J.T., 1987. GnRH secretion throughout the ovine estrous cy:le. Neuroendocrinology, 46: 82-88.

Clarke, I.J., Cummins, J.T., Jenkin, M. and Phillips, D.J., 1989. The oestrogen-induced surge of LH requires a 'signal' pattern of gonadotrophin-releasing hormone input to the pituitary gland in the ewe. J. Endocrinol., 122: 127-134.

Cumming, I.A., Buckmaster, J.M., Cerini, J.C., Cerini, M.E., Chamley, W.A., Findlay, J.K. and 
Goding, J.R. 1972. Effect of progesterone on release of luteinizing hormone induced by a synthetic gonadotropin-releasing factor in the ewe. Neuroendocrinology, 10: 338-348.

Dománski, E., Chomicka, L.K., Ostrowska, A., Gajewska, A. and Mateusiak, K, 1991. Kelease of luteinizing hormone-releasing hormone, $\beta$-endorphin and norcurenaline by the nucleus infundibularis/median eminence daring periovulatory period in the sheep. Neuroendocrinology, 5i. 151-158.

Goodman, R.L., 1988. Neuroendocrire control of the ovine estrous cycle. In: E. Knobil and J.D. Neill (Editurs), The Physiology of Reproduction. Raven Press, New York, pp. 19291969.

Goodman, R.L., Legan, S.J., Ryan, K.D., Foster, D.L. and Karscli, F.J., 19\$1. Importance of variations in behavioural and feedback actions of oestradiol to the control of seasonal oreeding in the ewe. J. Indocrinol., 89: 229-240.

Karsch, F.J., Cummins, J.T., Thomas, G.B. and Clarke, I.J., 1987. Steroid feedback inhibition of pulsatile secretion of gonadotropin releasing hormone in the ewe. Biol. Reprod., 36: 1207 .1218.

Kasa-Vubu, J.Z., Dahl, G.E., Evans, N.P., Thrun, L.A., Moenter, S.M., Padmanabhan, V. and Karsch, F.J., 1992. Progesterone blocks the estradiol-induced gonadotropin discharge in the ewe by inhibiting the surge of gonadotropin-releasing hormone. Endocrinology, in press.

Kaynard, A.H., Malpaux, B., Robinson, J.E., Wayne, N.L. and Karsch, F.J., 1988. Importance of pituitary and neural actions of estradiol in induction of the luteinizing hormone surge in the ewe. Neuroendocrinology, 48: 296 303.

Knobil, E., Plant, T.M., Wildt, L., Belchetz, P.E. and Marshall, G., 1980. Control of the thesus monkey menstrual cycle: permissive role of hypothalamic gonadotropin-releasing hormone. Science, 207: 1371-1373.

Levine, J.E. and Ramirez, V.D., 1982. Luteinizing hormcne-releasing hormone releasc during the rat estrous cycle and after ovariectomy as estimated with push-pull cannulae. Endocrinology, 111: 1439-1448.

Levine, J.E., Norman, R.L., Gliessman, P.M., Oyamz. T.T., Bangsberg, D.R. and Spies, H.G., 1985. In vivo gonadotropin-releasing hormone release and senum luteinizing hormone me:surements in ovariectomized, estrogen-ireatec thesus macaques. Endocrinology, 117: $711-$ 721.

Marshall, F.H.A. and Verney, E.B., 1936. The occurrence of ovulation and pseudopregnancy in the rabbit, as a result of central nervous stimulation. J. Physiol. (London), 86: 327-336.

Martin, J.E., Tyrey, L., Everett, J.W. and Fellows, R.E., 1974. Variation in responsiveness to synthetic LH-releasing factor (LRF) in proestrous and diestrous-3 rats. Endocrinolog;, 94: 556-562.

McCann, S.M., Taleisnik, S. and Friedman, H.M., 1960. LH-releasing activity in hypothalamic extracts. Proc. Soc. Exp. Biol. Med., 104: 432-434.

Midgley, Jr., A.R. and Jaffe, R.B., 1966. Human luteinizing hormone in serum during the menstrual cycle: determination by radioimmunoassay. J. Clin. Endocrinol., Metab., 26: 13751381.

Moenter S.M., Caraty, A. and Karsch, F.J., 1990. The estradiol-induced surge of gonadotropinreleasing homone in the ewe. Endocrinology, 127: 1375-1384.

Moenter, S.M., Caraty, A., Locatelli, A. and Karsch, F.J., 1991. Pattern of gonadotropin-releasing hormone ( $\mathrm{GnRH}$ ) secretion leading up to ovulation in the ewe: existence of a preovulatory GinRH surge. Endocrinology, 129: 1175-1182.

Moenter, S.M., Brand, R.M., Midgley, Jr., A.R. and Karsch, F.J., 1992a. Dynamics of gonadotropin-releasing hormone release during a pulse. Enducrinulugy, 130; 503-510.

Moenter, S.M., Brand, R.C. and Karsch, F.J., 1992b. Dynamics of GnRH secretion during the GnRH surge: insights into the mechanism of GnRH surge induction. Endocrinology, 30 . 2978-2984. 
Monroe, S.E., Rebar, K.W., Gay, V.L. and Midgley, Jr., A.R., 1969. Radioimmunoassay determination of iuteinizing h.ormone during the estrous cycle of the rat. Endocrinolegy, $85: 720$ 724.

Niswender, G.D., Roche, J.F., Foster, D.L. and Midgley, Jr., A.R., 1968. Radioimmuncassay of serum levels of lutzinizing Lormone during the cycle and early pregnancy in ewes. Proc. Soc. Exp. Biol. Med., 129: 901-904.

Sarkar, D.K., Chiappa, S.A. and Fink, G., 1976. Gonadotropin-releasing hormone surge in proDestrous rats. Nature, 264: 461-463.

Schally, A.V., Arimusa, A., Babg, Y., Nair, R.M., Matsuo, J., Redding, T.W., Debeljuk, L. and White, W.F., !971. Isolation and properties of the FSH- and LH-reieasing hormone. Biochen. Biophys. Res. Cc1nmun. 43: 393-399.

Schillo, K.K., Leshin, L.S., Kuehl, D. and Jacksun, G.L., 1985. Simultaneous measurement of luteinizing hormone-releasing hormone and 'uteinizing homone during the estradiol-induced luteinizing hormone surge in the ovariectomized ewe. Biol. Reprod., 33: 644-692. 